\title{
STRUCTURE AND FUTURE DEVELOPMENT OF THE SERVICE SECTOR IN BANGLADESH
}

\begin{abstract}
SHAKILA SALAM
Bangladesh Agricultural University, BANGLADESH

e-mail: Shampa.bau@gmail.com

RECEIVED

15 August 2016

1 November 2016

JEL

CLASSIFICATION

D19, 014, 011, R20

KEYWORDS

agriculture, service, industry, GDP, Markov chain model

ABSTRACT

Over the last four decades, Bangladesh has experienced significant structural changes in the economy. Contributions of industry and service sectors have expanded, while contribution of agricultural sector to GDP and employment has immensely decreased. Nowadays, agriculture fails to attract people due to the less profitability nature of agriculture. On the other side, jobs in service and industry are seems more lucrative and profitable to them. Generally, economic growth of the country is represented by flourishing industry and service sectors. Among the sub-sectors, expansion of 'wholesale \& retail trade', 'transport, storage and communication', and 'financial intermediations' are mainly contributed the overall expansion of service sector in the economy. Household's participation in service sector has also increased day by day, which indicate the expansion of employment of this sector. It is projected that this trend will also continue in future and households will be more interested to participate in service sector than industry sector.
\end{abstract}

\section{Introduction}

For being developed, economy has to pass through various stages from traditional stage to high mass consumption stage (Rostow, 1960). Therefore, the basic shift in production from the primary (agriculture) to the secondary (industry) and further to the tertiary sector (service) represents the economic growth of the country. With the development of country's economy, agricultural sector's gross domestic product (GDP) contribution as well 
as employment of labor declines and replaced by industry and service sectors (Kalirajan, Singh, 2013). Structural changes among these economic sectors are the result of the country's economic growth, which pushes labor from agricultural sector to the industry and service sectors. Due to land and labor market existence, small subsistence based agriculture replaced by commercial agriculture. Labor productivity in both agricultural and non-agricultural sector increases owing to balanced distribution of labor between sectors.

Service sector deals with intangible goods rather than general commodity. It provides a wide range of activities where people can improve productivity, sustainability and performance by using their knowledge and time (Wikipedia, 2016). This sector represents the largest part of the economy around the world. Not only in high income countries (like as USA, Japan, France and etc.), also low-income countries (like as Bangladesh, Pakistan, India, Nepal and so on) service sector dominates the economy (Mukhopadhyaya, 2002). For instance, the share of service sector to GDP was $49.62 \%$ in 1980, which is increased to 54.05 percent in 2013-2014 in Bangladesh. The expanding nature of this sector along with provision of greater employment opportunities, poverty reduction and rapid economic growth are highly expected to continue in future.

Moreover, the importance of service sector in the economy is also discussed by many empirical and theoretical literatures (Islam, et al., 2012; UNCTAD, 2015; Raihan, 2013). As a developing country, Bangladesh also recognize its significance and improvement of service sector's performance, especially public administration capacity, judiciary, financial sector, transport and communication has already selected as the overall development goals to achieve (FYP, 2015). By considering the importance of this sector, the aim of this article is to discuss the structure and trends of service sector over time. This study also analyze changing pattern of different sector's participation and forecast future service sector's participation situation. The rest of the article is organized as follows. Second section describes the dataset and analytical procedure. Third section provides a brief overview of the structure of service sector comparing with other sectors over the years. In section four, result of the forecasting is reported and concluding remarks are presented in the last section.

\section{Data and empirical methodology}

The main data source for this study is a panel dataset of three specific periods (1988-2000-2008), conducted by Bangladesh Institute of Development Studies (BIDS), International Rice Research Institute (IRRI) and Bangladesh Rural Advancement Committee (BRAC). In 1987-1988 the benchmark survey was conducted by BIDS on 1246 rural households from 62 villages in 57 districts (Hossain, Bayes, 2009). Later in 2000 and 2008, same households were interviewed by IRRI and BRAC. Moreover, other required secondary information for this article is obtained from different publications of Bangladesh Bureau of Statistics (BBS).

Due to lack of available data for a longer time period, stationary Markov chain (MC) model is used in this study to assess the changes and predict participation of rural households in service sector of Bangladesh. Following MC model, it can be assumed that the probability of farm movement from one category at the period $t$ to another category at time $(t+1)$ is not depend on the earlier periods. Transition probability implies the likelihood for the movement of farm among categories in certain time period. A stationary first order Markov chain is presented as (Zimmermann \& Heckelei, 2012):

$$
n_{j t}=\sum_{i=1}^{J} n_{i t-1} P_{i j}
$$


This equation explains that, the number of farms $n$ in farm category $j(j=1, \ldots, J)$ at time period $t$ is equal to the sum over the total number of farms in all farm categories $i$ in the previous period $(t-1)$ multiplied by their respective transition probabilities $P_{i j}{ }^{1}$. Transition probability matrix, $P(J \times J)$ is a combination of all transition probabilities $P_{i j}$ :

$$
P=\left[\begin{array}{cccc}
P_{11} & P_{12} & \cdots & P_{1 J} \\
P_{21} & P_{22} & \cdots & P_{1 J} \\
\vdots & \vdots & \cdots & \vdots \\
P_{11} & P_{12} & \cdots & P_{I J}
\end{array}\right]
$$

The probabilities hold both non-negativity condition and adding-up condition:

$$
\begin{gathered}
1 \geq P_{i j} \geq 0 \\
\sum_{j=1}^{j} P_{i j}=1
\end{gathered}
$$

Transition probabilities of a farm that moves from farm type $i$ to farm type $j$ can be estimated by:

$$
\hat{P}_{i j}=\frac{m_{i j}}{\sum_{j=1}^{J} m_{i j}}
$$

Where $m_{i j}$ indicates the number of farm movements from farm category $i$ to farm category $j$ in a period of time. In this analysis, the term 'farm' is replaced by 'household' as the interest of this study is to analyze the changing pattern of household's participation in different economic sectors rather than farm size change. Therefore, farm movement from one farm category to another indicates household's movement from one sector to another.

\section{Structure of the economy}

Over the last three decades, with the liberalization of trade and promotion of foreign direct investment, Bangladesh economy has moved to the market-oriented from the controlled. In trade liberalization, service sector's liberalization especially in communication and financial sub-sectors has prioritized (CUTS, 2008). Expansion of service sector is considered as one of the influential factors for the economic growth of the country. During the last decades, industry and service sectors have been flourishing in expense of shrinking agricultural sector. The contribution of industry sector increased from 17.31 to $29.61 \%$ between the periods of 1980-1981 and 20132014 respectively, whereas agriculture's share declined from 33.07 to $16.33 \%$ (Table 1).

The contribution of service sector increased from 49.62 to $54.05 \%$ within these periods. Moreover, overall GDP was growing at a rate of $6.16 \%$ in 2013-2014, which was mostly possible due to the high growth rate of industry and service sectors. Comparing to other South Asian countries, a consistent growth of service sector is found in Bangladesh over the years. On an average the growth of the service sector was 5.83\% in 2013-2014, which was increased gradually from $3.55 \%$ in $1980-1981$.

${ }^{1}$ In this analysis, the numbers of household category indicates household's participation in different economic sectors or activities, which is equal to 3 in this case. 
Table 1. Share of broad sectors to GDP and growth rate during the period of 1980-2014

\begin{tabular}{lccccccccccc}
\hline \multicolumn{1}{c}{ Sectors } & $1980-1981$ & $1985-1986$ & $1990-1991$ & $1995-1996$ & $2000-2001$ & $2005-2006$ & $2010-2011$ & $2011-2012$ & $2012-2013$ & $2013-2014^{*}$ \\
\hline \multirow{2}{*}{ Agriculture } & 33.07 & 31.15 & 29.23 & 25.68 & 25.03 & 19.01 & 18.01 & 17.38 & 16.78 & 16.33 \\
& $(3.31)$ & $(3.31)$ & $(2.23)$ & $(3.10)$ & $(3.14)$ & $(5.50)$ & $(4.46)$ & $(3.01)$ & $(2.46)$ & $(3.35)$ \\
\hline \multirow{2}{*}{ Industry } & 17.31 & 19.13 & 21.04 & 24.87 & 26.20 & 25.40 & 27.38 & 28.08 & 29.00 & 29.61 \\
& $(5.13)$ & $(6.72)$ & $(4.57)$ & $(6.98)$ & $(7.45)$ & $(9.80)$ & $(9.02)$ & $(9.44)$ & $(9.64)$ & $(8.39)$ \\
\hline \multirow{2}{*}{ Service } & 49.62 & 49.73 & 49.73 & 49.45 & 48.77 & 55.59 & 54.61 & 54.54 & 54.22 & 54.05 \\
& $(3.55)$ & $(4.10)$ & $(3.28)$ & $(3.96)$ & $(5.53)$ & $(6.60)$ & $(6.22)$ & $(6.58)$ & $(5.51)$ & $(5.83)$ \\
\hline \multirow{2}{*}{ Total } & 100.00 & 100.00 & 100.00 & 100.00 & 100.00 & 100.00 & 100.00 & 100.00 & 100.00 & 100.00 \\
& $(3.74)$ & $(3.34)$ & $(3.24)$ & $(4.47)$ & $(5.41)$ & $(7.18)$ & $(6.64)$ & $(6.72)$ & $(6.14)$ & $(6.16)$ \\
\hline
\end{tabular}

Note: figures in the parentheses implies growth rate; " Provisional value.

Source: BER (2014).

Table 2 presents the GDP contribution of different sub-sectors under service sector. It is clear from this table that 'wholesale and retail trade', 'transport, storage and communication', 'real estate, renting and business activities', and 'community, social and personal services' are the major contributors to the higher GDP share of service sector. Though these four sub-sectors are contributed the major portions, the share of GDP contribution of 'real estate, renting and business activities', and 'community, social and personal services' sub-sectors are decreasing over the years.

Table 2. Sub-sectoral contribution of service sector to GDP between 2005-2006 and 2013-2014

\begin{tabular}{lrrrrrrrrr}
\hline \multicolumn{1}{c}{ Sub-sectors } & $2005-$ & $2006-$ & $2007-$ & $2008-$ & $2009-$ & $2010-$ & $2011-$ & $2012-$ & $2013-$ \\
& 2006 & 2007 & 2008 & 2009 & 2010 & 2011 & 2012 & 2013 & 2014 \\
\hline Wholesale \& retail trade & 24.51 & 24.94 & 25.29 & 25.48 & 25.57 & 25.67 & 25.71 & 25.88 & 26.05 \\
Hotel \& restaurants & 1.37 & 1.36 & 1.34 & 1.36 & 1.37 & 1.37 & 1.36 & 1.38 & 1.39 \\
Transport, storage \& communication & 18.27 & 18.77 & 19.22 & 19.76 & 20.15 & 20.56 & 21.07 & 21.21 & 21.35 \\
Financial intermediations & 5.59 & 5.59 & 5.49 & 5.23 & 5.25 & 5.48 & 5.89 & 6.09 & 6.27 \\
Real Estate, rent \& business & 14.91 & 14.53 & 14.26 & 14.10 & 13.88 & 13.57 & 13.24 & 13.04 & 12.86 \\
Public admin. \& defense & 5.54 & 5.65 & 5.69 & 5.79 & 5.94 & 6.10 & 6.14 & 6.20 & 6.27 \\
Education & 3.92 & 4.00 & 4.06 & 4.08 & 4.07 & 4.05 & 4.09 & 4.13 & 4.22 \\
Health \& social works & 3.65 & 3.60 & 3.61 & 3.54 & 3.57 & 3.57 & 3.48 & 3.47 & 3.44 \\
Community \& personal service & 22.24 & 21.56 & 21.04 & 20.65 & 20.20 & 19.63 & 19.03 & 18.61 & 18.17 \\
Total service & 100.00 & 100.00 & 100.00 & 100.00 & 100.00 & 100.00 & 100.00 & 100.00 & 100.00 \\
\hline
\end{tabular}

Source: BER (2014).

On an average, 'wholesale \& retail trade', and 'transport, storage and communication' provides almost half of the service sector's total GDP share to the economy. Besides, the sub-sectors 'financial intermediations', 'public administration \& defense' and 'education' have also increased gradually in the last decade. The economic growth of the country is triggered by the increasing share of these sub-sectors as well as whole service sector.

In case of employment, share of agricultural sector is still prominent, though it has persistently decreased since 1995-1996 (Figure 1). Within last three decades, this sector's share dropped from 63.82 to $47.5 \%$ (BBS, 
2010). On the other hand, service sector's employment is much lower than its contribution to country's GDP. In fact there is a large gap exist between the service sector's employment in rural and urban areas. For instance, in the urban area about $34.4 \%$ households were engaged in government and private owned service activities compared to $8.9 \%$ in the rural area (BBS, 2010).

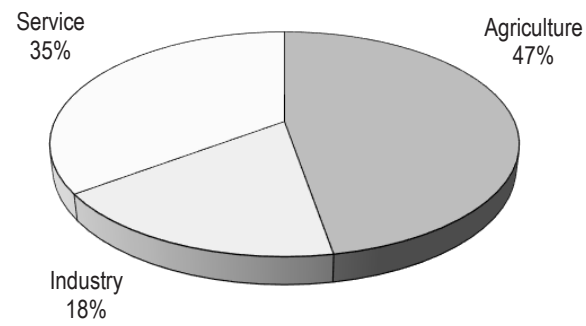

Figure 1. Sectoral composition of employment

Source: BBS (2010).

Table 3. Sub-sectoral composition of employment in service sector

\begin{tabular}{lccccc}
\hline \multirow{2}{*}{ Major Sub-sectors } & \multicolumn{5}{c}{ Employment share (\%) } \\
\cline { 2 - 6 } & $1995-1996$ & $1999-2000$ & $2002-2003$ & $2005-2006$ & 2010 \\
\hline Trade \& restaurants & 11.17 & 15.64 & 15.12 & 16.46 & 15.53 \\
Transport, storage \& communication & 4.21 & 6.41 & 6.77 & 8.44 & 7.39 \\
Finance \& business service & 0.37 & 1.03 & 0.68 & 1.69 & 1.85 \\
Public administration \& defense & & & 5.64 & 5.49 & 6.28 \\
Community, social \& personal services & 9.34 & 13.08 & 6.09 & 5.49 & 4.25 \\
Whole service sector & 25.00 & 23.50 & 34.60 & 40.90 & 42.90 \\
\hline
\end{tabular}

Source: BBS (2012).

However, employment in major sub-sectors of this service sector has shown an increasing tendency (Table 3). Employment in 'Community, social \& personal services' is decreasing from 1999-2000 to till today, whereas other major sub-sectors are increasing over the years. Liberalization of telecommunication and financial intermediaries during the late 1990s and early 2000s mainly promoted the growth of employment opportunities in service sector. On an average, employment in service sector grew from 25 to $42.90 \%$ within last two decades.

\section{Future development of the service sector}

Households in Bangladesh are involved in different types of economic activities for earning their livelihood and they are also moving from one activity group to another over the period (1988-2000-2008). These sources of economic activities are broadly classified into following three sectors: (1) Agriculture, (2) Industry and (3) Service. The total number of observation is 510, which is collected and balanced from panel data set (1988-2000-2008). Table 4 presents the average transition probability matrix, where standard deviations of the transition probabilities across seven regions and 3 time periods showed by the small italic numbers below the mean probability values. 
This transition probability matrix presents a typical pattern like other study on transition probability matrix (Zimmermann, Heckelei, 2012; Stokes, 2006), where the highest diagonal values of the matrix indicate the high probability to employ in the same sector like as previous time. In addition, the probability matrix also reveals lesser variability over time than region, which indicates changing sector's employment in different regions is much higher than they change it over time. Among the diagonal elements, highest value is found in household's employment in agricultural sector. Frequent movements among sectors are also found. Almost 20 and $25 \%$ of agriculture and industry based households are shifted to service based employment in 2008 as compare to 1988 respectively.

Table 4. Average transition probability of economic sectors (broad) change across regions \& over time (\%)

\begin{tabular}{lcccc}
\hline \multirow{2}{*}{ Economic activity in 1988} & \multicolumn{3}{c}{ Economic activity in 2008 } & Total \\
\cline { 2 - 4 } & agriculture & industry & service & 100.00 \\
\hline Agriculture & 67.95 & 11.88 & 20.17 & \\
SD region & 0.058 & 0.03 & 0.04 & 100.00 \\
SD time & 0.05 & 0.02 & 24.83 & \\
\hline Industry & 18.63 & 56.54 & 0.08 & 100.00 \\
SD region & 0.04 & 0.10 & 0.04 & \\
SD time & 0.02 & 0.14 & 61.70 & 0.09 \\
\hline Service & 22.76 & 15.54 & 0.02 & \\
SD region & 0.05 & 0.04 & & \\
SD time & 0.03 & 0.08 & & \\
\hline
\end{tabular}

Source: own calculation based on panel data of 1988-2008.

To examine the future economic sector's structure, estimated transition probability matrix is used to forecast for the years 2018 and 2028 (Table 5). Both forecasts provide same direction of future sectoral changes of employment. Overall, the forecast suggests squeezing of agricultural activities and flourishing of industry and service sectors compared to the base period (2008). Household losing their interest on farming activities over the years, as farming is not a profitable business in Bangladesh nowadays. Moreover, household's participation in service sector will increase by $41.64 \%$ in 2018 and $58.31 \%$ in 2028 , which are comparatively higher than industry sector in rural Bangladesh.

Table 5. Projected distribution of rural sectoral employment (\%)

\begin{tabular}{lccccc}
\hline \multirow{2}{*}{ Economic activity } & Percentage in base level & \multicolumn{2}{c}{ Projection for 2018 } & \multicolumn{2}{c}{ Projection for 2028 } \\
\cline { 3 - 5 } & $(2008)$ & 2018 & change & 2028 & change \\
\hline Agriculture & 62.71 & 50.85 & -18.91 & 44.07 & -29.72 \\
Industry & 16.95 & 20.34 & 20.00 & 23.73 & 40.00 \\
Service & 20.34 & 28.81 & 41.64 & 32.20 & 58.31 \\
\hline Total & 100.00 & 100.00 & & 100.00 & \\
\hline
\end{tabular}

Source: own calculation based on panel data of 1988-2008.

\section{Conclusions}

Expansion of service sector's contribution is one of the strengths of the country's economic development. Bangladesh economy has experienced significant change in the sectoral composition during last few decades. 
Contribution of agriculture to GDP and employment has been decreasing in expense of increasing trend of industry and service sectors. Though overall service sector is improving day by day, there are some sub-sectors which are not expanding. Special attention should be provided on these sectors that will make service sector more forward. Besides, there are enough rooms for further improvement of service sector with the expansion of rapidly growing industry sector. For instance, export service, tourism, and hotel services are the area to be more developed in the near future.

Households, even rural households are now more interested to involve in service sector than agriculture or industry sector. Therefore, service activities should be decentralized and widely expand in rural areas. The requirement of education and financial services are increasing in rural areas and Bangladesh as well. Policy makers should consider all of these possible options to be make service sector and economy more developed.

\section{Refierence}

BBS (2010). Labor Force Survey. Bangladesh Bureau of statistics, Statistics Division. Ministry of Planning, Government of the Peoples Republic of Bangladesh, Dhaka, Bangladesh.

BBS (2012). Statistical Yearbook of Bangladesh, Bangladesh Bureau of statistics. Ministry of Planning, Government of the Peoples Republic of Bangladesh, Dhaka, Bangladesh.

BER (2014). Bangladesh Economic Review. Government of the People's Republic of Bangladesh. Ministry of Finance, Dhaka, Bangladesh.

CUTS (2008). Evolution of Service Sector in Bangladesh: An Overview. Available at: http:// www.cuts-citee.org/pdf/Briefing_Paper08Evolution_of_Service_Sector_in_Bangladesh. pdf.pdf (6.08.2016).

FYP (2015). Seventh five year plan FY2016-FY2020. Accelerating Growth, Empowering Citizens. Final Draft. General Economics Division (GED). Planning Commission, Government of the People's Republic of Bangladesh.

Hossain, M. \& Bayes, A. (2009). Rural Economy and Livelihoods Insights from Bangladesh. A H Development Publishing House, Dhaka, Bangladesh.

Islam, M.S., Musa, M. \& Das, R.K. (2012). The Comparative Growth of Service Sectors in Bangladesh. Research Journal of Finance and Accounting, 3 (5), 178-186.

Kalirajan, K. \& Singh, K. (2013). Understanding sectoral economic growth in India: The potential for services. Institutions and Economics, 5, 91-112.

Mukhopadhyaya, S. (2002). Globalisation and Indian Services Sector. Economic and Political Weekly, 38 (40), 4097-4098.

Raihan, D.S. (2013). Trade and employment in information technology (IT) services in Bangladesh. Available at: http://www.lo.org/ wcmsp5/groups/public/---asia/---ro-bangkok/---ilo-dhaka/documents/briefingnote/wcms_203521.pdf (6.08.2016).

Rostow, W.W. (1960). The Stages of Economic Growth: A Non-Communist Manifesto. Cambridge University Press.

Stokes, J.R. (2006). Entry, exit, and structural change in Pennsylvania's dairy sector. Agricultural and Resource Economics Review, $35,357-373$.

UNCTAD (2015). Trade in services: Bangladesh context. Multi-year expert meeting on trade, service and development. Available at: http://unctad.org/meetings/en/Presentation/c1mem3_2015_p15_Ahmed_en.pdf (2.08.2016).

Wikipedia, (2016). Tertiary sector of the economy. The free encyclopedia. Available at: https://en.wikipedia.org/wiki/Tertiary_sector_ of_the_economy (2.08.2016).

Zimmermann, A. \& Heckelei, T. (2012a). Differences of farm structural change across European regions. Discussion Paper 2012:4, Agricultural and Resource Economics, University of Bonn, Germany.

Cite this article aS: Salam, S. (2016). Structure and future development of the service sector in Bangladesh. European Journal of Service Management, 20 (4), 49-55. DOI: 10.18276/ejsm.2016.20-06. 
